\title{
Gesturing for oneself
}

\author{
Harun Zurina • Julian Williams
}

Published online: 18 January 2011

(C) Springer Science+Business Media B.V. 2011

\begin{abstract}
Most research on gestures (especially in the field of Mathematics Education) has focused on gestures in communication with others. In contrast, here, we focus on gestures which are not directed at others, but which we assume accompany inner speech or embodied thought, such as the gesticulation one makes by touching one's fingers whilst silently counting; that is, whilst thinking, or communicating with oneself. Typically, these gestures are accompanied by eye gaze, which is detached from others who are present and turned either inwards or towards relevant artefacts present. Additionally, these gestures-whilst structurally similar-are much smaller than "normal" gestures used in interpersonal communication, suggesting an attenuation parallel to that found in inner speech. These physical gestures are in effect objectifications for oneself, which we can interpret as a not-quite-yet "underground" part of embodied thought. We suggest that they might be particularly vital for understanding the imagistic, visuospatial dimension of mathematics in general and fractions in particular.
\end{abstract}

Keywords Gestures · Self gestures · Inner speech · Embodied mathematics · Fractions · Visuospatial

H. Zurina $(\bowtie) \cdot J$. Williams

University of Manchester, Manchester, UK

e-mail: zurinaharun@hotmail.com

J. Williams

e-mail: julian.williams@manchester.ac.uk 


\section{Introduction}

Please try this little activity: we think it will help with what follows.

\section{Counting the Star of David-Part 1}

1. With closed eyes, imagine two overlapping triangles in a six pointed star of David, with a bead placed on each node (i.e., each point of intersection of the edges);

2. Count the beads, without verbalizing and without gesturing, that is no moving your hands or fingers.

\section{Part 2}

1. Open your eyes;

2. Try to describe your experience - what did you "see" in your mind's eye? How did you count the beads? Did you move your head at all as you counted?

Note: Repeat the activity a second time, but this time you may use your hand in whatever way you want ... does it help you to count to yourself?

We both tried this activity and, not surprisingly, got the wrong answer when we did not allow ourselves to use gestures. We believe that most people would imagine a "pointer" such as an imaginary finger to help them mentally frame the two triangles in their visual spatial field and point to each of the beads as they count them off in inner speech: "one", "two", and so forth, perhaps nodding their head in rhythm with the counting to help intensify the thought. Whilst counting the beads, some inner speech involving "internal" counting would be occurring. This internal counting would be inner speech with rhythmic, internal gesticulating using imaginary "pointers" or fingers, but might be accompanied by slight, perhaps visible objectifications such as nodding of the head, or even externalised egocentric speech if necessary.

In the case where the use of one's hand is permitted, we predict that the inner counting may be accompanied by some external visible gestures with the hand and/or fingers, whether consciously or not. We use the term gesture here to mean "movements of the arms and hands...closely synchronized with the flow of speech" (McNeill, 1992, p. 11). We suppose that this is also commonly what happens to students when they are faced with a mental task, especially when they are faced with one that is difficult. Their thought or inner speech is likely to be accompanied by some form of external gesturing. In this paper, we want to look at such gestures which we believe are not directed at communication with others, but rather that embody thought, or accompany inner speech-such as the gesture one might employ in the above activity - silently counting whilst communicating with oneself. In fact, extrapolating from McNeill's theory, we shall assume that gestures and language (in our case inner language) indissolubly together form speech (in our case inner speech).

The episodes presented and analysed are extracts from experimental lessons in which students were engaging in activities pertaining to fractions and are selected to give readers the opportunity to see what McNeill (2005) called the two "dimensions of meaning" in inner speech. We believe that such gestures are important for mathematics education as they could contribute to the students' mathematics knowing and thinking, especially when they are engaging in thought when faced with difficult tasks. However, we realise that an alternative interpretation of these gestures might be that there was no mathematical understanding or meaning, and the gestures occurred as a means of 
appearing to understand (as can be seen when children in classrooms "half" raise their hands to answer a teacher's question). All we can say is that we did not believe- - on close examination - that this was the case here: but we leave space for the reader to construct multiple interpretations. In short, generally, the characteristics of the gestures that we are focusing on are those which are accompanied by eye gaze (and the whole body disposition) which is detached from others present, either turned inwards or towards relevant artefacts present. These gestures are also much smaller and closer to the gesturer's body than those used in interpersonal communications, indicating an attenuation parallel to that of inner speech.

Following Vygotsky, we regard bodily-actions-that-become-gestures as preceding interpersonal communication phylogenetically and ontogenetically. The gesture proper is borne out of an action that is given meaning in interaction: thus, the child reaches out to a desired object, the parent interprets the need and delivers the object to the child, and the child subsequently learns; as Vygotsky observes "The grasping movement changes to the act of pointing...a true gesture" (Vygotsky, 1978, p. 56). Similarly, speech is shaped in social interaction alongside gestures: Vygotsky prescribes a key role for embodiment in early communication, when the meaning of the child's first cries is interpreted by the carer in the context of his or her whole bodily disposition. Thus, gestures can be seen alongside verbalisation in the earliest interactional speech long before the child develops "egocentric speech" (e.g. in play), long before intrapersonal control and planning in speech-for-oneself (Vygotsky, 2000, p. 32), and certainly before it "goes underground" into "inner speech":

The cognitive function of egocentric speech, which is most probably connected with the development of inner speech, by no means is a reflection of the child's egocentric thinking, but rather shows that under certain circumstances egocentric speech is becoming an agent of realistic thinking. (Vygotsky, 2000, p. 33)

Let us add here a remark by Kozulin that the whole direction of Vygotsky's theory leads to "gestures-for-oneself" accompanying speech-for-oneself, both in egocentric and in inner speech (Kozulin, p. xxxvii in Vygotsky, 2000). When we talk of gestures for oneself, this is what we refer to: in the following analyses, they will be assumed to be part of inner communication, indissolubly bound up with inner speech, or even sometimes replacing its linguistic dimension.

Vygotsky $(1978,2000)$ formed a clear view about how speech is transformed into verbal thought on the "intrapsychological plane"-it becomes attenuated and forms a kind of "psychic predicate" that incorporates word-meaning; he was also explicit about the key role of gestures in symbolic play. But he was less clear about the transformation of gestures and embodied signs generally with inner speech or thought. McNeill (2005), however, developed a specific "image-verbal" dialectical theory of the "growth point" (hereafter, GP) that he claims offers just this: for McNeill, meaning in the higher cognitive functioning of thought or speech is a dialectical combination of two dimensions of meaning: the embodied-imagistic-active-dynamic dimension (grounded in the gestural/embodied component of speech) and a verbal-linguistic dimension of meaning that we usually identify in Vygotsky's unit of "word-meaning" (McNeill, 2005). Thus, speech is realised by an unfolding of gesture and verbalisation from a growth point that emerges from a psychic unit of meaning-itself consisting of a dialectic of image-and-verbalisation (note that this verbalisation might consist of part-words or utterance components). Following Vygotsky's principle regarding internalisation via inner speech or thought (e.g. when problem-solving), McNeill's theory takes us to "thought" as some possibly transformed version of this 
dialectical process of unfolding in which gestures for oneself might play a key role alongside inner speech.

...the gesture, the actual motion of gesture itself, is a dimension of meaning. Such is possible if the gesture is the very image; not an "expression" or "representation" of it, but is it...a gesture is an image in its most developed - that is, most materially, naturally embodied-form. (McNeill, 2005, p. 98)

For the moment, we leave the detail of GP theory: the main point is that such gestures, when accompanying speech, serve a number of vital meaning-making functions that complement (or, actually contradict) verbalisation, that intensify the image dimension of the meaning, and that might be critical to visuospatial communication. Goldin-Meadow (2005, 2006) also suggested that gestures intensify thoughts and so, we infer, help alleviate the cognitive burden of silent inner communication and thought. But we know that much mathematics, if not all, depends on embodied, enactive and visuospatial grounding (Lakoff \& Nunez, 1997, 2000; Nunez, Edwards, \& Matos, 1999). In the context of fractions and rational numbers in particular, spatial models, diagrams and embodied actions are regarded as vital (see, e.g. Behr, Harel, Post, \& Lesh, 1992; Empson, Junk, Domingues, \& Turner, 2005; Monroe \& Nelson, 2002). In studies of trainee teachers' knowledge of fractions in particular, we know that gestures appear to be significant and include indexical and iconic gesture signs for cutting parts (Edwards, 2009).

Indeed, it is argued in Realistic Mathematics Education (hereafter, RME) that effective pedagogy must generate models, images and a visuospatial dimension to mathematical meaning-making for young learners (see, e.g. Williams, 2009). The argument is that physical-spatial pedagogical models allow enactive and embodied acts of mathematical objectification that are likely to precede formal linguistic/mathematical semiotic developments just as gestures precede linguistic expressions more generally (see, e.g. Ryan \& Williams, 2007; also Kendon, 2004). And in our design of the activities which yield the following episodes, we gave models, drawings and cutting a significant role (Zurina, 2010).

Radford $(2006,2008)$ has indeed described the conditions under which mathematical objectifications are likely to become social and "generalised" and constructed his theory of objectification in similar contexts: it is widely accepted that more intimate interpersonal gestural objectifications are likely to precede the formal "contextual" and symbolic generalisation stages. Radford's conception of objectification is not, however, synonymous with gestures as depicted by Vygotsky (1978) when he discussed internalisation. Vygotsky defined internalisation as an "internal reconstruction of an external operation" (p. 56), where the gesture moved from an individual plane (gesture-in-itself) to the social plane (gesture-for-others) and finally back to the individual plane (gesture-for-oneself, according to Kozulin, in Vygotsky, 2000). Having said this, our context of fractions was not particularly designed to research "gestures for oneself" per se: as said above, we chanced on these and must assume that they are as likely to occur in any such RME-like modelling activities, no matter the curriculum domain.

In each of the following episodes, then, we identify and investigate an occurrence of a gesture that appeared to us not to be addressed to another person (e.g. we could see that the gesturer made no eye contact with an interlocutor but rather seemed self-absorbed), but rather seemed to indicate that the learner was making some meaning for him or herself, whilst reflecting for the moment alone. We found in each case that a particular gesture materialised, embodied and thus intensified a thought or perhaps some internal speech, and thus served primarily to draw their (i.e. Nora's and Zak's) own attention to the "object" of the gesture. This is what we mean by a gesture for oneself, or an objectification for oneself. 
The "self" here is both embodied and social and is consistent with Vygotsky's use of the term.

\section{Gesturing to the self in an activity involving part-of-a-whole in fractions}

The episodes that we will discuss in the next two sections are part of a study that Zurina had carried out for her $\mathrm{PhD}$ project with 36 Form 1 students (i.e. 12-year-olds, equivalent to year 7 in the UK) on fractions. It is a commonly accepted view by educators and researchers that of all topics in the primary school curriculum, "fractions" is the hardest (see, e.g. Cramer, Post, \& delMas, 2002). On top of that, many of the research studies done in this area involved primary children, with notable exceptions (see, e.g. Lamon, 1996, whose models influenced our teaching design here).

Behr et al. (1992) suggested that the part-whole subconstruct, which they interpreted using a unit analysis, led to two interpretations of rational numbers - that is, as part of a whole and as a composite part of a whole. Similarly, in this episode, the task was to cut a 12-in. cheese bread into six equal pieces. Once they had cut the pieces, the teacher led a discussion regarding the size of each of the six small pieces in terms of fractions, in terms of the number of parts and also in terms of the bread's length in inches. For this part of the discussion, the students gave the correct responses, and prior to this episode, Hiz, Lan and Zak all gave 1 over 6 as the fraction in terms of the number of parts, and also 2 over 12 as the fraction in terms of the lengths in inches for one of the cut piece. Once that had been established, the teacher put two of the pieces together (Fig. 1), and one student, Zak, frowned and looked confused.

\section{Episode 1}

1. ZH: That's (points to one out of six cut piece) one over six. If there's two of this, how much is that?

2. Hiz\&Zak: Two over six.

3. ZH: Give me another fraction. How long will these (points to two out of six cut pieces) be?

4. Zak: Four over twelve.

5. Hiz: Four over...eight...eh....

6. Ain: Four over twelve.

7. ZH: Four over 12 because the total is 12 . So this is as you said two over six.

8. Zak: (Looked confused with 4 over 12 and 2 over 6 . He asked Hiz something but inaudibly_our guess from reading his lips, "Not 2 over 12?”)

Zak seemed to be confused momentarily with the fractions for the two parts. Earlier (lines 2 and 4), whilst working with Hiz and Ain, he was able to give the correct fractions of 2 over 6 and 4 over 12 for the bread when asked separately, but when the teacher was summarizing what they had said - that the bread is 2 over 6 and also 4 over 12 - he looked confused, perhaps thinking that it should be 2 over 12 instead of 4 over 12 . Zak at this point did not "see" that the two fractions that he and the others had given earlier were in fact equivalent, one in terms of the number of parts and the other in terms of its length. One

Fig. 1 Schematic representation of the six cut pieces with two of the pieces grouped together

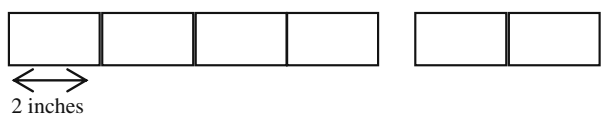


possible explanation for Zak's uncertainty about the equivalence of the two fractions might be that the words used to describe them were different from the written representations-2 over 6 (two sixths) and 4 over 12 (four twelfths), $\frac{2}{6}$ and $\frac{4}{12}$ (Mamede, Nunes, \& Bryant, 2005). Also, I (ZH) presumed this was because of the two parts involved, overlooking the fact that we were dealing earlier with the length, which is in inches. Hiz, who sat on his right (line 5), had also been unsure of his response when hesitantly giving an answer of "4 over 8". This, I (ZH) presumed, might be because of the way the cut pieces of bread were arranged (see Fig. 1) with a group with four of the six pieces and another group with two of the six pieces. However, when Zak asked (from my guess in line 8) "Not 2 over 12?" Hiz, in line 1 (episode 2), explained and stressed the word "inches" and pointed out that it has two parts (Fig. 2); from Hiz's own response, it appeared most likely that he managed to correct himself. This seemed to direct Zak's attention back to the length of the bread for the two parts so that he was able to connect that the length of each part is two inches, hence four inches for the two parts, thus objectifying equivalence. It can be said that Hiz was the one who first objectified the equivalence, followed by Zak objectifying it to himself when he nodded to himself, looked at the bread, pointed at the two pieces (Fig. 3), counted the parts again to himself and finally nodded his head again (see http://stream.manchester.ac. uk/Play.aspx?VideoId=5592 for Zak's gestures). Zak's first nod to himself might be interpreted as his acknowledging and/or accepting Hiz's explanation, and his second nod might be interpreted as a sign to himself (without any external speech) that he had understood, though it might be he was trying to communicate to the teacher $(\mathrm{ZH})$ and Hiz that he "got" it. It might be that here Zak's inner speech reorganizing his thought was intensified by this self-gesturing.

\section{Episode 2}

1. Hiz: That (pointing to two out of the six slices, see Fig. 3) is four over twelve... inches...that's (points to one out of six cut piece) two...

2. Zak: The parts?

3. Hiz: Yes.

4. Zak: (nods to himself, looks at the bread, points and counts the parts of the bread to himself $^{1}$ and nods again seemingly to himself, see Figs. 3 and 4).

Zak's counting gestures (Fig. 3), when examined closely, were in fact small and close to his face and body when compared to typical pointing gestures accompanying communication, such as Hiz's (Fig. 2) lower arm movement throughout the snapshots. In addition to this minute movement, where most of the counting motion was made by his index finger (for only approximately 2 seconds in Fig. 3), he was at the same time looking at the cut pieces of bread. This diminutive movement together with his gaze, fixed on the slices as he counted, gives a strong indication that his gestures were not directed to others; rather, they were gestures to himself, which could be accompanying internal counting. In other words, from the moment Zak said "the parts" (line 3, episode 2) and Hiz's "yes" (line 4, episode 2), his communicative speech went underground to an inner form of "speech-for-oneself" (Vygotsky, 2000, p. 32), that is, inner speech. The only visible evidence that we can present here that this is actually happening is from what Zak externalized; his nodding to himself, looking at the bread (i.e. we infer inner counting), gesturally counting (i.e. pointing at) them and then again nodding to himself. Checking for himself requires inner counting, and so it

\footnotetext{
${ }^{1}$ Follow this link (http://stream.manchester.ac.uk/Play.aspx?VideoId=5592) to view Zak’s gestures.
} 
Fig. 2 Hiz pointing to two of the six cut pieces

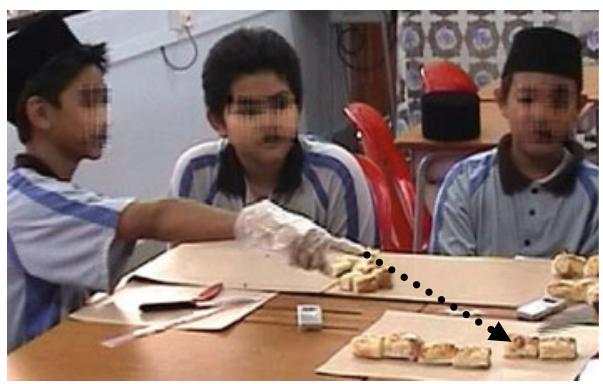

might have triggered the pointing gestures dialectically coupled with his inner speech. This is in line, we believe, with Vygotsky's theory of the shifting of "communication-for-others" to "individualized reasoning-for-oneself" (Kozulin, p. xxxvi, in Vygotsky, 2000), which he also referred to as shifting "interpersonal communication" to "intrapersonal communication" and "inner, intrapsychological mental functions" (Kozulin, p. xxxvi, in Vygotsky, 2000). We interpret Zak's visible gesture as being an indissoluble part of "inner counting" and as having the same function in communication with the self as it does when accompanying speech proper in communicating with others. This may be open to other interpretations, for as Vygotsky (2000) said, "To study an internal process, it is necessary to externalize it..." (p. 227). Thus, in order to interpret what mental functions Zak had to have gone through, we closely examine Zak's externalized gestures and bodily actions and draw inferences regarding the linguistic components that assure a meaningful unit of inner mathematical speech-for-oneself.

Why did this occur? We believe that his pointing gesture served to focus his own attention on the pieces of bread and his inner counting reaffirmed that there were only six pieces of bread there. Finally, from Zak's nodding gestures after counting the cut pieces, it could be concluded that he "agreed" that 2 over 6 was the same as 4 over 12 .

We therefore agree with Radford (2009) that these gestures are part of the objectification of (rather than merely "accompanying", or provide a window on) thought itself, which here is conceived of as intrapersonal communication. Thus, his objectification here is "to" and for himself. But in order to interpret this objectification, we infer a necessary linguistic counting component of the inner speech.
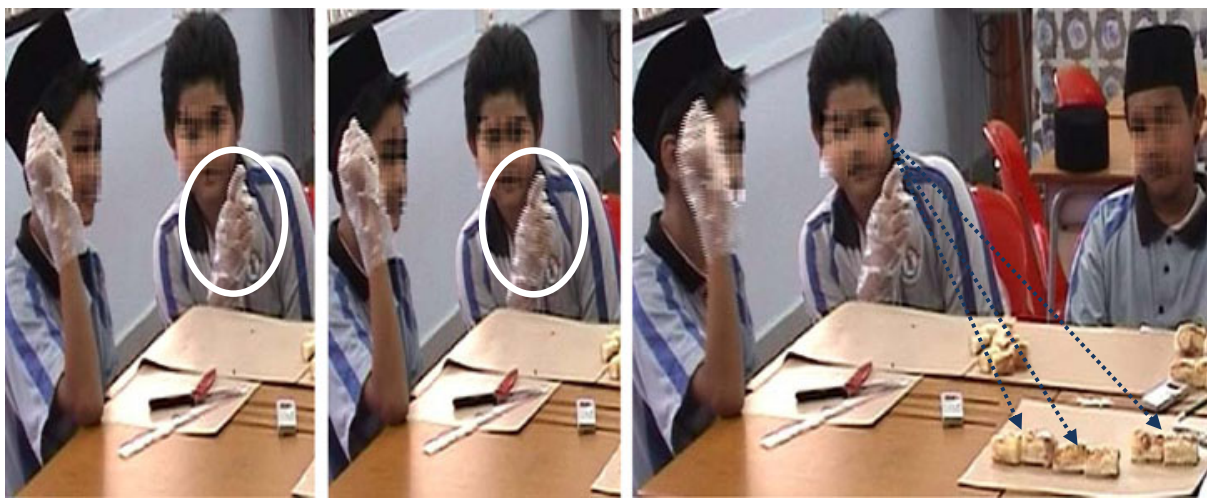

Fig. 3 Zak's (second from left) pointing at the cut bread and counting the number of cut pieces, eyes focused on the bread, with no "outer" speech (http://stream.manchester.ac.uk/Play.aspx?VideoId=5592) 
Fig. 4 Sketch of Zak's index finger movement
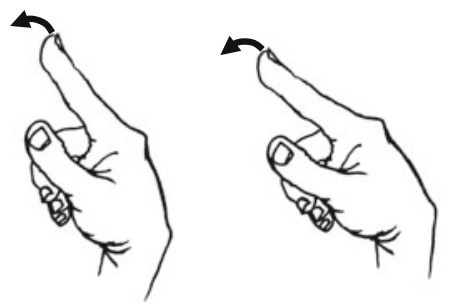

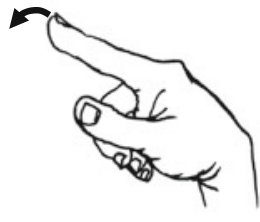

\section{Gesturing and visualising}

The following episode was extracted from a card game activity which involved the idea of sharing. The students were provided with a pack of blue cards that said "If I have this number of cake(s)" a pack of yellow cards that said "I want to divide them equally between this numbers of children". The possible number of cake(s) in this activity was one whole cake, two whole cakes, $\frac{1}{2}$ of a cake, $\frac{1}{3}$ of a cake and $\frac{1}{4}$ of a cake, and the possible number of children to share the cake(s) was two, three or four.

In this particular episode, Haris picked a blue card with two whole cakes and a yellow card with three.

\section{Episode 3}

1. ZH: [...] So you have two cakes shared between three people, so how?

2. Wan: What if we put them together? (referring to the 2 cakes)

3. Haris: Can we put them together? (gesturing with both hands with thumbs pointing upwards and moving both hands towards each other to indicate putting the "two cakes" together)

4. ZH: Sure, but you still have to consider it as two cakes, it's up to you but you don't consider it as one cake. It's still two cakes (places two pieces of paper to represent the two cakes).

5. Haris: (gestures a three-stroke chopping motion across the two "cakes" (i.e. two pieces of paper; refer to Fig. 5)

6. Nora: (looks up, repeats Haris's three-stroke chopping gestures, frowns, followed by showing "scissor" sign with two fingers, and a two-stroke chopping motion ${ }^{2}$ ). Two over three (see Figs. 6, 7 and 8).

In episode 3, Wan and Haris tried to overcome the problem by suggesting that the cakes be put together, and the teacher informed them that they could do so but cautioned that they still had to consider the combined cake as two separate cakes as that would be the unit in this case. Noticing that the students were struggling with the idea of two cakes shared between three people, the teacher pulled out two pieces of paper to represent the cakes so that they could focus on the two "cakes". At this stage, Haris gestured with his right hand to indicate how to cut them by gesturing three-stroke chopping motion across the two "cakes" (Fig. 5), which would in fact cut the cakes into four shares instead of three as required. Following this, Nora, who was sitting on the teacher's right, gestured to herself, copying the chopping motion that Haris performed; she frowned, looking puzzled with her eyes looking upwards (Fig. 6). At that moment, Nora's frown indicated that she apparently faced a difficult situation and was probably trying to process and assess Haris's response (i.e. the three chopping strokes). By repeating (mimicking) Haris's three chopping motions, she

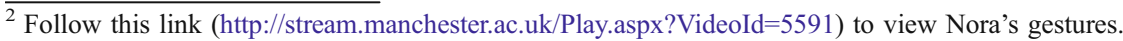



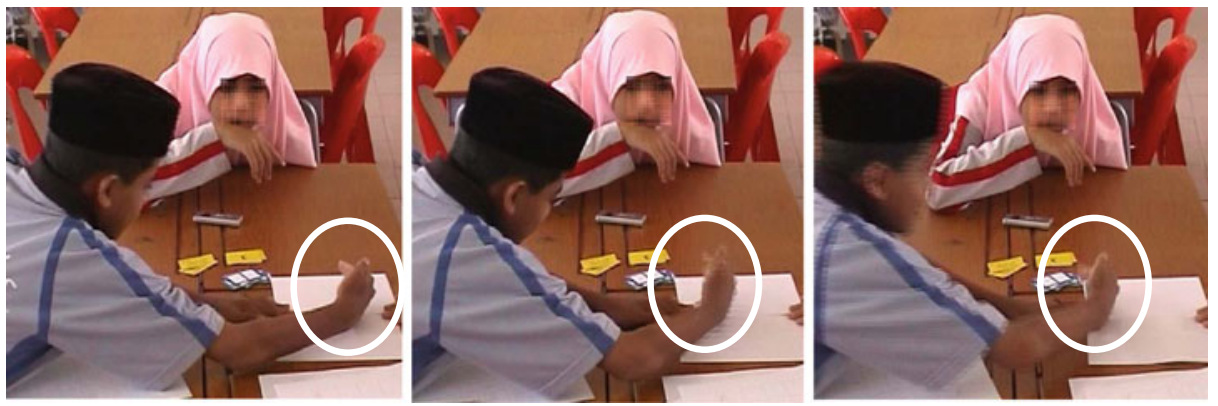

Fig. 5 Haris (first left) performing the three strokes

made the objectification available to her own perception a second time, allowing for a reflective evaluation of the chopping motions.

At this moment of reflection, she frowned again, apparently experiencing some conflict. She then signed "2" with a V-shaped "scissor-handed" gesture of the forefinger and middle finger (see Fig. 7 and http://stream.manchester.ac.uk/Play.aspx?VideoId=5591) and with the same hand chopped two times with her finger horizontally, which was parallel to the horizontal slicing in Fig. 8, apparently objectifying for herself the division of the two cakes into three parts (see Fig. 8 and http://stream.manchester.ac.uk/Play.aspx?VideoId=5591). Here, Nora objectified the quantity to be divided by her V-sign which needed to be divided into three equal parts by two horizontal cuts. Like Zak, she finally nodded to herself, which could be an indication for herself of a completion of the process to her satisfaction. Her answer was confirmed when the teacher asked her for an explanation, at which point she said "Divide each into three, then two pieces for each" (episode 4).

Episode 4

1. Nora replied: Divide each into three, then two pieces for each.

In Nora's case, her gestures-for-herself might be considered as deictic and iconic, just like when communicating with others. Her gestures were small and confined to a small part
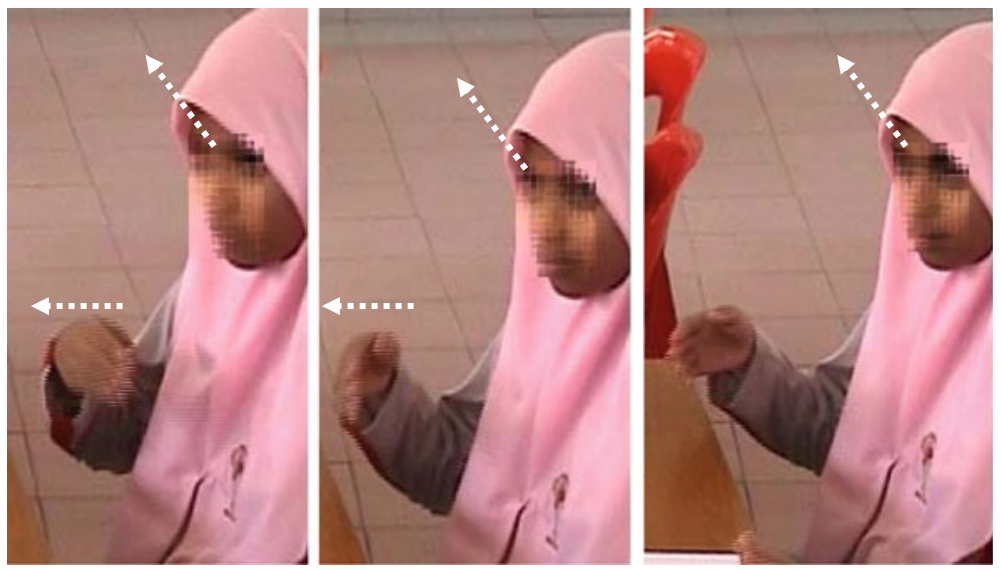

Fig. 6 Nora gesturing (i.e. repeating Haris's gestures) the three-stroke cutting motion with her eyes looking slightly upwards throughout (http://stream.manchester.ac.uk/Play.aspx?VideoId=5591) 
Fig. 7 Nora gesturing a V-sign with her fingers with her eyes looking downwards (http:// stream.manchester.ac.uk/Play. aspx? VideoId $=5591$ )

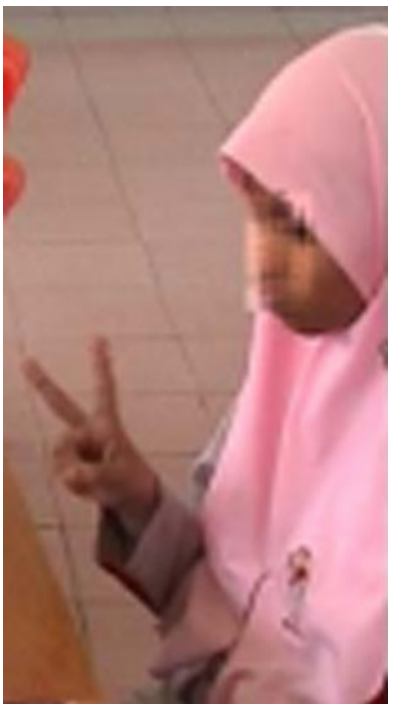

of her virtual space (as defined by Sabena et al. 2009 and Yoon, Thomas, \& Dreyfus 2009). Throughout, there no was no eye-contact with others present: she was in fact looking slightly upwards, with a gaze that typically is interpreted as her accompanying internal thought or self-communication.

This incident is interesting in a number of ways, suggesting some complexity of functions of self-gestures. Notice, for instance, that Nora attends to Haris's gestures and interprets his "three chops" as indicating three cuts rather than three pieces. Copying this gesture, we infer, may lighten the load of her internal visualisation of the result - this process apparently facilitated by her eyes physically "withdrawing from others present" in a characteristic "eyes up into the head" movement. Having thus (in Fig. 6) confirmed her doubt about Haris's objectifications, a "V-shaped scissors" signing "2" (Fig. 7) and two

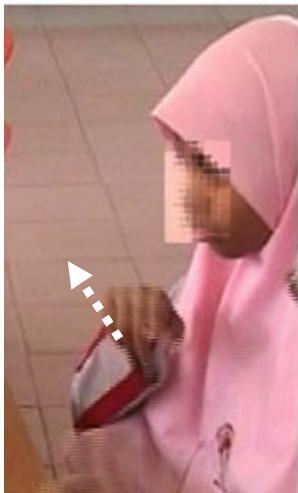

Picture 1

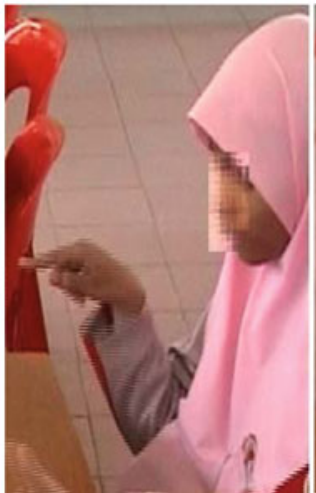

Picture 2

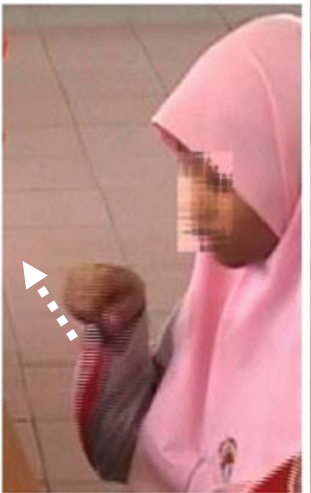

Picture 3

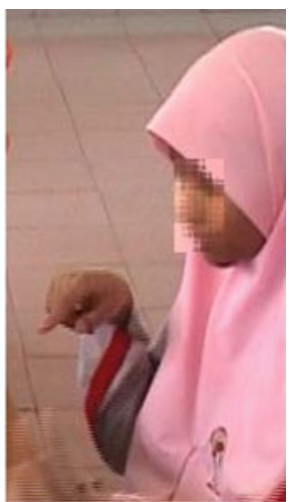

Picture 4

Fig. 8 Nora gesturing the two-cutting strokes-picture 1 and picture 2 show the first stroke (moving from left to right); picture 3 and picture 4 show the second stroke, also from left to right (http://stream.manchester. ac.uk/Play.aspx?VideoId=5591) 
Fig. 9 Schematic representation of the division of the cakes
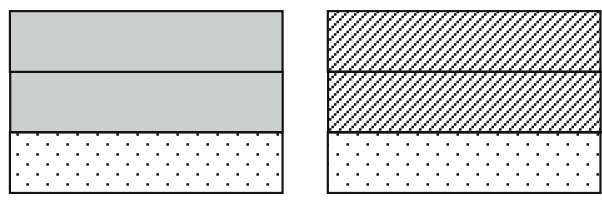

horizontal slices with her forefinger acting like a pen, Nora (Fig. 8) apparently constructed a visualisation like that of Fig. 9.

\section{Concluding remarks}

In each case, the gestures for the self we focused on appeared to be directed at no one else present, and no eye contact with others present was occurring at the crucial moment. The gestures are diminutive and the gaze is turned inward, away from others or the group centre, or towards some artefact present (e.g. line 4, episode 2). We argue that these are likely to be features characteristic of gestures for oneself as they help withdraw and intensify attention inwardly when reflecting.

These gestures seemed to be stimulated by a need for a degree of reflection caused by some dissonance in the group work: some problem needing to be resolved that involves breaking off communication with the group for at least a moment. The structure of the body movement was sometimes similar to the gesture one would expect to accompany "external" speech addressed to the group: we find it persuasive that such gestures-foroneself are the residue of gestures originally accompanying (or part of) speech for others that have almost-but not quite- "gone underground": the need for an embodiment of the thought represents a need to intensify or add a visuospatial, enactive dimension to a thought or an inner utterance. Thus, when trying to count the beads on the nodes of the Star of David (chosen to extend beyond the visual field normally achievable in subitization), we feel the need to intensify the visualisation by embodied indexical actions (eye or head movements) or specifically by gestures or hand movements that accompany our inner verbalisation of counting. This then-we think likely - is what Hiz was doing as he counted in episode 1. His nod of the head, however, was not indexical and did not accompany counting here; rather, it was a symbolic gesture to himself that accompanied-or perhaps substituted for-the inner verbalization such as: “Got it, now!" Thus, as Radford (2006) stated:

Gestures helped the students visualize (Presmeg, 2006) and thereby came to fill the gap left by impossible direct perception. Generally speaking, gestures do not merely carry out intentions or information; they are key elements of the process of knowledge objectification. (p. 16)

But note that in our interpretation (that is, in constructing a mathematical meaning for this act), we feel forced to infer the other dimensions involved that might make up the dialectical unit of inner communication, the unit-of-inner-communication-meaning that we think Vygotsky might have developed from word-meaning (were he working today). In episode 2, Haris and Nora are communicating with gestures. Even if Haris does not know it, when he makes three strokes of the hand and Nora frowns, we infer that her dissonance is incited by her thought that he is incorrectly symbolising the cutting into four parts. At this moment, she breaks off (gaze averts), and we infer she is imagining the result of cutting by three cuts into four parts: her own gesture embodies and 
objectifies these three cuts, thus intensifying the image she seeks to reevaluate. McNeill might say - after Goldin-Meadows - that the gesture would serve to intensify the image dimension of her meaning, which is co-expressive with a linguistic dimension that (in speech) would be saying something like "three cuts making four parts".

However, the point is that if there is inner speech, that is a linguistic component of their inner communication, we cannot hear it; we only observe the gestural component of it in these cases. In McNeil's theory, it is not suggested that the gesture accompanying outer speech is a mere epiphenomenon: for McNeill, communication is embodied (objectifying its imagistic dimension of meaning) as well as verbalised in speech (carrying the linguistic dimension of meaning). Similarly then, when communication goes inward, there may be gestural as well as linguistic components. Instead of Vygotsky's "word-meaning" unit that bridges language and thought, we have instead a "communication-meaning" unit, or "wordplus-gesture-meaning" as the unit of communication and thought, where communicationmeaning here is the indivisible dialectical unity of both embodied/active/imagistic and linguistic components. (Actually, instead of 'word' we would do better to say 'utterance' or 'part-utterance', as McNeill and other neo-Vygotskyans have pointed out.) What we are seeing when learners are communicating with themselves are gestures that objectify the imagistic dimensions of inner communication, which are the last visible remnants of imagistic thought.

In Radford's theory of objectification, there is no separate "inner plane" as in Vygotsky's theory; the objectification comprises the thought and the sign. In pure semiotics, there are only signs that are interpreted with new signs, but to this, Radford adds the dimension of awareness and sensuous, embodied cognition, which we find helpful. Thus, we drew on our own personal experience of our own imagistic work in the experiment with the Star of David because we sought a subjective reference from which to interpret the episodes above. We have to leave it to the reader to judge the validity of such phenomenology.

Likewise, we must appeal to the reader to validate the general value of this work for mathematics education: we believe that these gestures to oneself provide us with a representation of the enactive and imagistic work that learners of mathematics engage in when learning fractions through models and modelling and in group activities. However, we believe that there is a strong case for attending more to such gestures to oneself as part of the embodied, egocentric mathematics that learners enact and think for themselves. We notice that such gestures bridge interpersonal interactions with intrapersonal reflection, but also that their sense is largely structured by the mathematical models that such gestures index-research on gestures therefore holds out the prospect of influencing the design of pedagogical models. At least we want to know that these models are designed so that children can gesture, that is, insert their bodies into the spaces appropriately so that salient mathematical features of the model are clearly visible, "graspable" and index-able.

We also know (e.g. from Sabena et al., 2009) that teachers can use learners' spontaneous gestures effectively, and indeed that powerful gestures might be introduced by the teacher, or even that powerful gestures might "go viral" in our mathematics education culture. All we need to do is locate such powerful gestures and discover what "powerful" means in this context. We suspect that the fraction "cut" might be one such candidate, much like the Cshape was in the studies cited in Williams (2009).

Whilst many researchers have investigated the use of gestures without words in various contexts of communication (e.g. when gestures replace words for the deaf), we are not aware of any case in which this involves egocentric or reflective, inner speech 
(communication with oneself using gestures directed at oneself as the addressee) and certainly not in mathematics education. So there remains much to be done.

\section{References}

Behr, M. J., Harel, G., Post, T., \& Lesh, R. (1992). Rational number, ratio, proportion. In D. A. Grouws (Ed.), Handbook of research on mathematics teaching and learning (pp. 296-333). New York: Macmillan.

Cramer, K. A., Post, T. R., \& delMas, R. C. (2002). Initial fraction learning by fourth- and fifth-grade students: A comparison of the effects of using commercial curricula with the effects of using the rational number project curriculum. Journal for Research in Mathematics Education, 33(2), 111-143.

Edwards, L. (2009). Gestures and conceptual integration in mathematical talk. Educational Studies in Mathematics, 70, 127-141.

Empson, S. B., Junk, D., Dominguez, H., \& Turner, E. (2005). Fractions as the coordination of multiplicatively related quantities: A cross-sectional study of children's thinking. In T. Dreyfus, B. Barton, P. Boero, N. C. Presmeg, \& H. Steinbring (Eds.). Educational Studies in Mathematics, 63, 1-28.

Goldin-Meadow, S. (2005). The two faces of gestures: Language and thought. Gesture, 5, 241-257.

Goldin-Meadow, S. (2006). Talking and thinking with our hands. Current Directions in Psychological Science, 15, 34-39.

Kendon, A. (2004). Reviews [Review of the hearing gesture: How our hands help us think, by S. GoldinMeadow]. Gesture, 4, 91-107.

Lakoff, G., \& Nunez, R. (1997). The metaphorical structure of mathematics: Sketching out cognitive foundation for a mind-based mathematics. In L. English (Ed.), Mathematical reasoning: Analogies, metaphors and images (pp. 21-89). New Jersey: Erlbaum.

Lakoff, G., \& Nunez, R. (2000). Where mathematics comes from: How the embodied mind brings mathematics into being. New York: Basic Books.

Lamon, S. J. (1996). The development of unitizing: Its role in children's partitioning strategies. Journal for Research in Mathematics Education, 2, 170-193.

Mamede, E., Nunes, T., \& Bryant, P. (2005). The equivalence and ordering of fractions in part-whole and quotient situations. In H. L. Chick \& J. L. Vincent (Eds.), Proceedings of the 29th Conference of the International Group for the Psychology of Mathematics Education (Vol. 3, pp. 281-288). Australia: University of Melbourne.

McNeill, D. (1992). Hand and mind. Chicago: University of Chicago Press.

McNeill, D. (2005). Gesture and thought. Chicago: University of Chicago Press.

Monroe, E. E., \& Nelson, M. (2002). Egg cartons revisited. In G. Dunn, R. Stewart, and H. Williams (Eds.). Mathematics Teaching, 179, 11-14.

Nunez, R., Edwards, L., \& Matos, J. F. (1999). Embodied cognition as grounding for situatedness and context in mathematics education. Educational Studies in Mathematics, 39(1-3), 45-65.

Radford, L. (2005). Why do gestures matter? Gestures as semiotic means of objectification. In H. L. Chick \& J. L. Vincent (Eds.), Proceedings of the 29th Conference of the International Group for the Psychology of Mathematics Education (Vol. 1, pp. 143-145). Australia: University of Melbourne.

Radford, L. (2006). Algebraic thinking and the generalization of patterns: A semiotic perspective. In S. Alatorre, J. L. Cortina, M. Saiz, \& A. Mendez (Eds.), Proceedings of the 28th annual meeting of the North American Chapter of the International Group for the Psychology of Mathematics Education (Vol. 1, pp. 2-21). Mérida: Universidad Pedagógica Nacional.

Radford, L. (2008). The ethics of being and knowing: Towards a cultural theory of learning. In L. Radford, G. Schubring, \& F. Seeger (Eds.), Semiotics in mathematics education: Epistemology, history, classroom and culture (pp. 215-234). Rotterdam: Sense Publishers.

Radford, L. (2009). Why gestures matter? Sensuous cognition and the palpability of mathematical meanings. Educational Studies in Mathematics, 70(3), 111-126.

Ryan, J., \& Williams, J. (2007). Children's mathematics 4-15: Learning from errors and misconceptions. UK: Open University Press.

Sabena, C., Yoon, C., Arzarello, F., Dreyfus, T., Paola, D., \& Thomas, M. (2009). Relationships and control within semiotic bundles. In M. Tzekaki, M. Kaldrimidou, \& H. Sakonidis (Eds.), Proceedings of the 33rd Conference of the International Group for the Psychology of Mathematics Education (Vol. 5, pp. 33-40). Greece: PME.

Vygotsky, L. (1978). Mind in society. In Cole, M., John-Steiner, V., Scribner, S., \& Souberman, E. (Eds.). Cambridge, MA: Harvard University Press. 
Vygotsky, L. (2000) (Original, 1934). Thought and language (A. Kozulin, Ed. \& Trans.). USA: MIT.

Williams, J. (2009). Embodied multi-modal communication from the perspective of activity theory. Educational Studies of Mathematics, 70, 201-210.

Yoon, C., Thomas, M. O. J., \& Dreyfus, T. (2009). Gestures and virtual space. In M. Tzekaki, M. Kaldrimidou, \& H. Sakonidis (Eds.), Proceedings of the 33rd Conference of the International Group for the Psychology of Mathematics Education (Vol. 5, pp. 409-416). Greece: PME.

Zurina Harun (2010). Evaluating the teaching and learning of fractions through modelling in Brunei: Measurement and semiotic analyses. Thesis, University of Manchester, Manchester, UK. 